\title{
What are the Risk Factors for Cerebrovascular Accidents After Elective Orthopaedic Surgery?
}

\author{
Shobhit V. Minhas MD, Preeya Goyal BA, Alpesh A. Patel MD
}

Received: 29 April 2015/Accepted: 31 July 2015/Published online: 20 August 2015

(C) The Association of Bone and Joint Surgeons (B) 2015

\begin{abstract}
Background Perioperative cerebrovascular accidents (CVAs) are one of the leading causes of patient morbidity, mortality, and medical costs. However, little is known regarding the rates of these events and risk factors for CVA after elective orthopaedic surgery.

Questions/purposes Our goals were to (1) establish the national, baseline proportion of patients experiencing a
\end{abstract}

\begin{abstract}
One of the authors certifies that he (AAP), or a member of his or her immediate family, has or may receive payments or benefits, during the study period, an amount of USD 10,000-USD 100,000, from Amedica (Salt Lake City, UT, USA); an amount of less than USD 10,000 from Ulrich (Chesterfield, MO, USA); an amount of less than USD 10,000 from Cytonics (West Palm Beach, FL, USA); an amount of less than USD 10,000 from Nocimed (Redwood City, CA, USA); an amount of less than USD 10,000 from Vital (Campbell, CA, USA); an amount of less than USD 10,000 from Biomet (Warsaw, IN, USA); an amount of USD 10,000-USD 100,000 from DePuy (Warsaw, IN, USA); an amount of less than USD 10,000 from Stryker (Kalamazoo, MI, USA); and an amount of less than USD 10,000 from Zimmer (Warsaw, IN, USA), outside the submitted work.

All ICMJE Conflict of Interest Forms for authors and Clinical Orthopaedics and Related Research ${ }^{\circledR}$ editors and board members are on file with the publication and can be viewed on request.
\end{abstract}

S. V. Minhas

Department of Orthopaedic Surgery, Hospital for Joint Diseases, NYU School of Medicine, New York, NY, USA

P. Goyal, A. A. Patel

Department of Orthopaedic Surgery, Feinberg School of

Medicine, Northwestern University, Chicago, IL, USA

\section{A. A. Patel ( $\square)$}

Department of Orthopaedic Surgery, Feinberg School of Medicine, Northwestern University, 676 North Saint Clair Street, NMH/Arkes Family Pavilion, Suite 1350, Chicago, IL 60611, USA

e-mail: shobhitvishnoi2@gmail.com 30-day CVA and the timing of CVA; and (2) determine independent risk factors for 30-day CVA rates after common elective orthopaedic procedures.

Methods Patients undergoing elective TKA, THA, posterior or posterolateral lumbar fusion, anterior cervical discectomy and fusion, and total shoulder arthroplasty, from 2006 to 2012, were identified from the American College of Surgeons National Surgical Quality Improvement Program ${ }^{\mathbb{R}}$ database. A total of 42,150 patients met inclusion criteria. Thirty-day CVA rates were recorded for each procedure, and patients were assessed for characteristics associated with CVA through univariate analysis. Multivariate regression models were created to identify independent risk factors for CVA.

Results A total of $55(0.13 \%)$ patients experienced a CVA within 30 days of the procedure, occurring a median of 2 days after surgery (range, 1-30 days) with $0.08 \%$ of patients experiencing a CVA after TKA, $0.15 \%$ after THA, $0.00 \%$ after single-level anterior cervical discectomy and fusion, $0.38 \%$ after multilevel anterior cervical discectomy and fusions, $0.20 \%$ after single-level posterior or posterolateral lumbar fusion, $0.70 \%$ after multilevel posterior or posterolateral lumbar fusion, and $0.22 \%$ after total shoulder arthroplasty. Independent risk factors for CVA included age of 75 years or older (odds ratio [OR], 2.50; 95\% CI, 1.44-4.35; $\mathrm{p}=0.001$ ), insulin-dependent diabetes mellitus (OR, 3.08; CI, 1.47-6.45; $\mathrm{p}=0.003)$, hypertension (OR, $2.71 ; \mathrm{CI}, 1.19-6.13 ; \mathrm{p}=0.017)$, history of transient ischemic attack (OR, 2.83; CI, 1.24-6.45; $\mathrm{p}=0.013)$, dyspnea (OR, 2.51; CI, 1.30-4.86; $\mathrm{p}=0.006)$, chronic obstructive pulmonary disease (OR, 2.33; CI, 1.06-5.13; $\mathrm{p}=0.036$ ), and operative time of 180 minutes or greater (OR, 3.25; CI 1.60-6.60; $\mathrm{p}=0.001$ ).

Conclusions Numerous nonmodifiable patient comorbidities and increased operative time were associated with 
CVA after elective orthopaedic procedures. However, the American College of Surgeons National Surgical Quality Improvement Program ${ }^{\mathbb{R}}$ database does not code for cardiac arrhythmia or atrial fibrillation, which other studies have suggested may be important predictor variables; those may be important risk factors, although we were unable to evaluate them in our study. Surgeons should counsel patients with these risk factors and limit their operative time to reduce the risk of these adverse events, and future studies should examine other patient characteristics such as arrhythmia and noncoronary heart disease and assess the role of pharmacologic prophylaxis in patients with these risk factors.

Level of Evidence Level III, prognostic study.

\section{Introduction}

Cerebrovascular accidents (CVAs) are a leading cause of disability in the United States, affecting almost 800,000 patients annually and contributing to substantial postincidence morbidity, mortality, and more than USD 33 billion in annual medical expenditures [30]. Additionally, stroke is projected to be the second leading cause of worldwide mortality through 2020 while remaining the largest contributor to adult neurologic disability [31]. The perioperative period places patients at an even greater risk of CVA owing to surgery-induced hypercoagulability, general anesthesia, dehydration, stasis and bed rest, and withholding administration of preoperative antiplatelet and anticoagulation agents [38]. Despite advances in surgical techniques and perioperative care, the incidence of stroke has remained stable, varying by the type and complexity of operative intervention [16, 22, 29, 32, 37].

The proportion of patients experiencing a CVA after general surgery procedures range from $0.08 \%$ to $0.7 \%$ to as much as $10 \%$ for complex cardiac operations, yet epidemiologic data concerning orthopaedic surgery have been minimal $[8,14,23,26]$. Although previous studies directly examining CVA rates and predictors have shown $0.1 \%$ to $0.2 \%$ of patients experienced a CVA after THA, TKA, and lumbar arthrodesis [24, 29], information regarding other elective inpatient procedures has been limited to small cohorts or case reports [11, 22, 24, 29]. These studies have shown that history of neurologic disorders, congestive heart failure, electrolyte imbalances, noncoronary heart disease, nonelective surgery, general anesthesia, and intraoperative arrhythmia were associated with these events, depending on the procedure. Although CVA rates have been deemed relatively low after orthopaedic intervention [11, 22, 24, 29], determining patients at high risk and CVA timing is crucial for detailed preoperative counseling, thorough perioperative inpatient monitoring and prevention, and appropriate postoperative followup.

We therefore analyzed a large, national cohort of patients undergoing common elective inpatient orthopaedic procedures through the use of the American College of Surgeons National Surgical Quality Improvement Program $^{\circledR}$ (ACS NSQIP ${ }^{\circledR}$ ) database [1]. Specifically, our goals are to (1) establish baseline, national 30-day CVA proportions and timing; and (2) determine independent risk factors for 30-day CVA after common elective orthopaedic procedures.

\section{Patients and Methods}

A retrospective cohort analysis of the ACS NSQIP ${ }^{\circledR}$ database from 2006 to 2012 was performed. Patient variables from more than 250 participating institutions nationwide are included in the ACS NSQIP ${ }^{\circledR}$, and this database has been used to analyze trends and associations in orthopaedic surgery $[15,17,28]$. The method of data abstraction from the ACS NSQIP ${ }^{\circledR}$ participant files has been described [4, 18]. Patients were identified through Current Procedural Terminology (CPT) codes and included patients undergoing TKA (CPT 27447), THA (CPT 27130), single-level posterior or posterolateral lumbar fusion (CPT 22612 with no CPT modifiers), multilevel posterior or posterolateral lumbar fusion (CPT 22612 with a CPT modifier of 22614), single-level anterior cervical discectomy and fusion (CPT 22551 with no CPT modifiers), multilevel anterior cervical discectomy and fusions (CPT 22612 with a CPT modifier of 22552), and total shoulder arthroplasty (CPT 23472). Exclusion criteria included "emergency" or "nonelective" cases (labeled in the ACS NSQIP ${ }^{\circledR}$ database as "emergency surgery occurring within a short interval from diagnosis to surgery, ... and outcome is potentially threatened by unnecessary delay and the patient's status could deteriorate unpredictably or rapidly, and ... the emergency case variable distinguishes between urgent, semi-elective/elective cases and true emergencies" and each hospital's definition of outpatient, respectively [1]. Exclusion criteria also included outpatient surgery, patients with preoperative sepsis or systemic inflammatory response syndrome, patients with prior surgery within 30 days of the index procedure, cases with missing preoperative or operative variables $(n=49,343 ; 49.7 \%)$, and cases with unrelated additional concurrent procedures (such as bilateral sameday TKA, bilateral same-day THA, and anterior instrumentation in posterior or posterolateral lumbar fusion,). Following these selection criteria, a total of 42,150 patients of an original 99,285 were included in our final analysis (Fig. 1). These included 22,900 (54\%) patients 


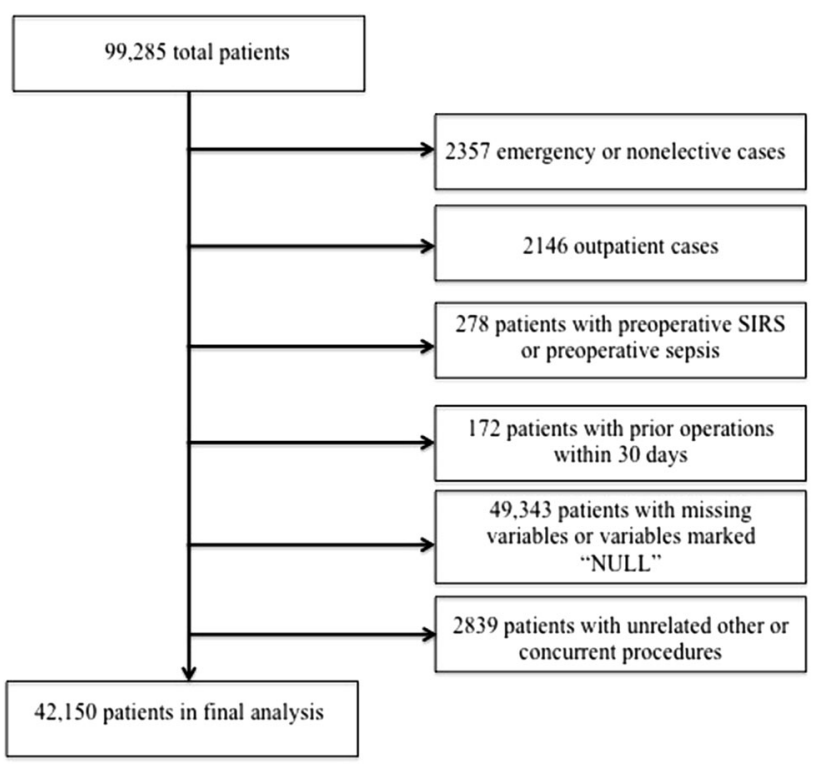

Fig. 1 The flowchart for our study is shown. SIRS = systemic inflammatory response syndrome.

who had TKAs; 13,437 (32\%) who had THAs; 604 (1\%) who had a single-level anterior cervical discectomy and fusion; $527(1 \%)$ who had multilevel anterior cervical discectomies and fusions; 2042 (5\%) who had a singlelevel posterior or posterolateral lumbar fusion; 853 (2\%) who had multilevel posterior or posterolateral lumbar fusions; and 1787 (4\%) who had total shoulder arthroplasty.

The primary outcome was CVA within 30 days of the index procedure and was defined by the ACS-NSQIP ${ }^{\circledR}$ participant use files as "an embolic, thrombotic, or hemorrhagic vascular accident or stroke with motor, sensory, or cognitive dysfunction (eg, hemiplegia, hemiparesis, aphasia, sensory deficit, impaired memory) that persists for 24 or more hours" [1]. CVA timing (day of CVA event after surgery and pre- versus postdischarge events) also was recorded. Preoperative and operative variables were captured for each patient, including those previously shown to be associated with perioperative stroke, such as age, prior history of CVA, hypertension, diabetes, prior myocardial infarction, congestive heart failure, and general anesthesia (Table 1) [22, 24, 29, 32, 38].

IBM SPSS ${ }^{\circledR}$ Version 22.0 (IBM Corp, Armonk, NY, USA) was used for all descriptive and comparative analyses in this study. In all cases, a p value of 0.05 or less was deemed statistically significant. Patients were split in two groups: those with a 30-day CVA and those without. Univariate analysis of preoperative and operative variables between the two cohorts was conducted through the Fisher's exact test. Multivariate logistic multivariate regression
Table 1. Patient characteristics

\begin{tabular}{|c|c|c|}
\hline Variable & $\begin{array}{l}\text { Number of } \\
\text { patients }\end{array}$ & Percentage \\
\hline Male sex & 16,799 & $40 \%$ \\
\hline Age $\geq 75$ years & 10,283 & $24 \%$ \\
\hline $\mathrm{BMI} \geq 30 \mathrm{~kg} / \mathrm{m}^{2}$ & 22,534 & $53 \%$ \\
\hline Functional dependence & 1871 & $4 \%$ \\
\hline Current smoker & 4867 & $12 \%$ \\
\hline Insulin-dependent diabetes mellitus & 1659 & $4 \%$ \\
\hline Noninsulin-dependent diabetes mellitus & 4933 & $12 \%$ \\
\hline Hypertension & 26,791 & $64 \%$ \\
\hline $\begin{array}{l}\text { History of myocardial infarction or } \\
\text { percutaneous coronary intervention }\end{array}$ & 2694 & $6 \%$ \\
\hline History of transient ischemic attack & 1178 & $3 \%$ \\
\hline History of cerebrovascular accident & 1213 & $3 \%$ \\
\hline $\begin{array}{l}\text { Recent congestive heart failure } \\
\text { exacerbation }\end{array}$ & 73 & $0 \%$ \\
\hline Dyspnea & 3530 & $8 \%$ \\
\hline Peripheral vascular disease or rest pain & 309 & $1 \%$ \\
\hline Current malignancy & 184 & $0 \%$ \\
\hline Ascites or esophageal varices & 17 & $0 \%$ \\
\hline Chronic obstructive pulmonary disease & 1654 & $4 \%$ \\
\hline Dialysis & 63 & $0 \%$ \\
\hline Preoperative creatinine $\geq 2 \mathrm{mg} / \mathrm{dL}$ & 1488 & $4 \%$ \\
\hline Chronic steroid use & 1301 & $3 \%$ \\
\hline Bleeding disorder & 1018 & $2 \%$ \\
\hline Preoperative hematocrit $\leq 37 \%$ & 8752 & $21 \%$ \\
\hline ASA Class $\geq 3$ & 19,303 & $46 \%$ \\
\hline Operative time $\geq 180$ minutes & 3068 & $7 \%$ \\
\hline General anesthesia & 24,507 & $58 \%$ \\
\hline TKA & 22,900 & $54 \%$ \\
\hline THA & 13,437 & $32 \%$ \\
\hline $\begin{array}{l}\text { Single-level anterior cervical discectomy } \\
\text { and fusion }\end{array}$ & 604 & $1 \%$ \\
\hline $\begin{array}{l}\text { Multilevel anterior cervical discectomy } \\
\text { and fusion }\end{array}$ & 527 & $1 \%$ \\
\hline $\begin{array}{l}\text { Single-level posterior or posterolateral } \\
\text { lumbar fusion }\end{array}$ & 2042 & $5 \%$ \\
\hline $\begin{array}{l}\text { Multilevel posterior or posterolateral } \\
\text { lumbar fusion }\end{array}$ & 853 & $2 \%$ \\
\hline Total shoulder arthroplasty & 1787 & $4 \%$ \\
\hline
\end{tabular}

ASA $=$ American Society of Anesthesiologists.

models were created to determine independent risk factors for CVA. Candidate variables were screened from the original univariate analysis, and variables with $\mathrm{p}$ less than 0.2 and at least five incidences were included [33]. Hosmer-Lemeshow and c-statistics were calculated to assess the calibration and goodness of fit of the multivariate analysis, respectively [27]. 


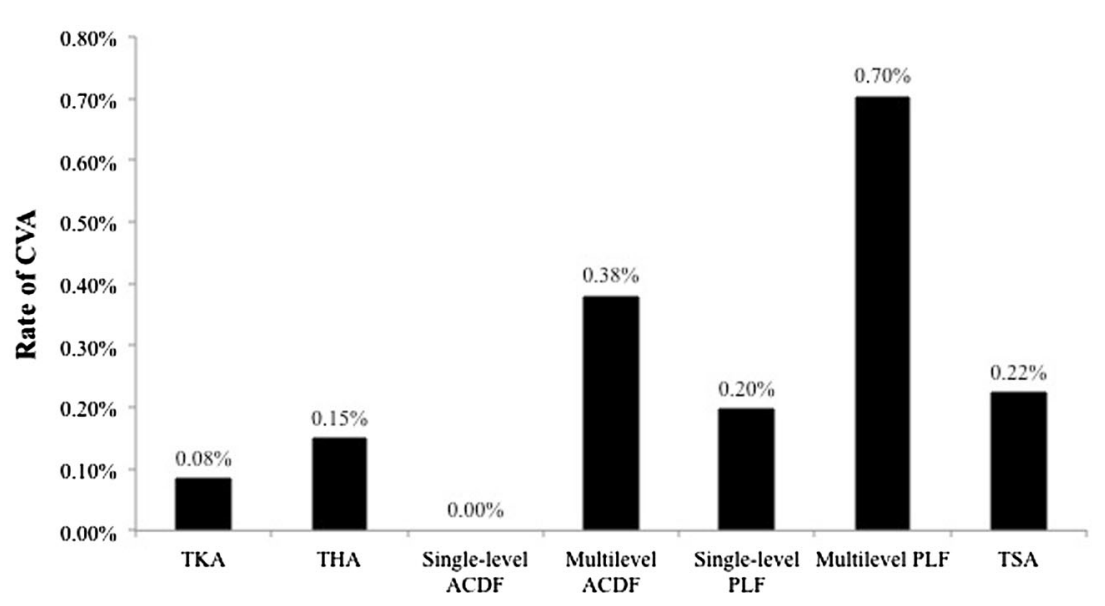

Fig. 2 The proportion of patients with a 30-day cerebrovascular accident (CVA) by procedure is shown. ACDF = anterior cervical discectomy and fusion; PLF $=$ posterior or posterolateral lumbar fusion; TSA = total shoulder arthroplasty.

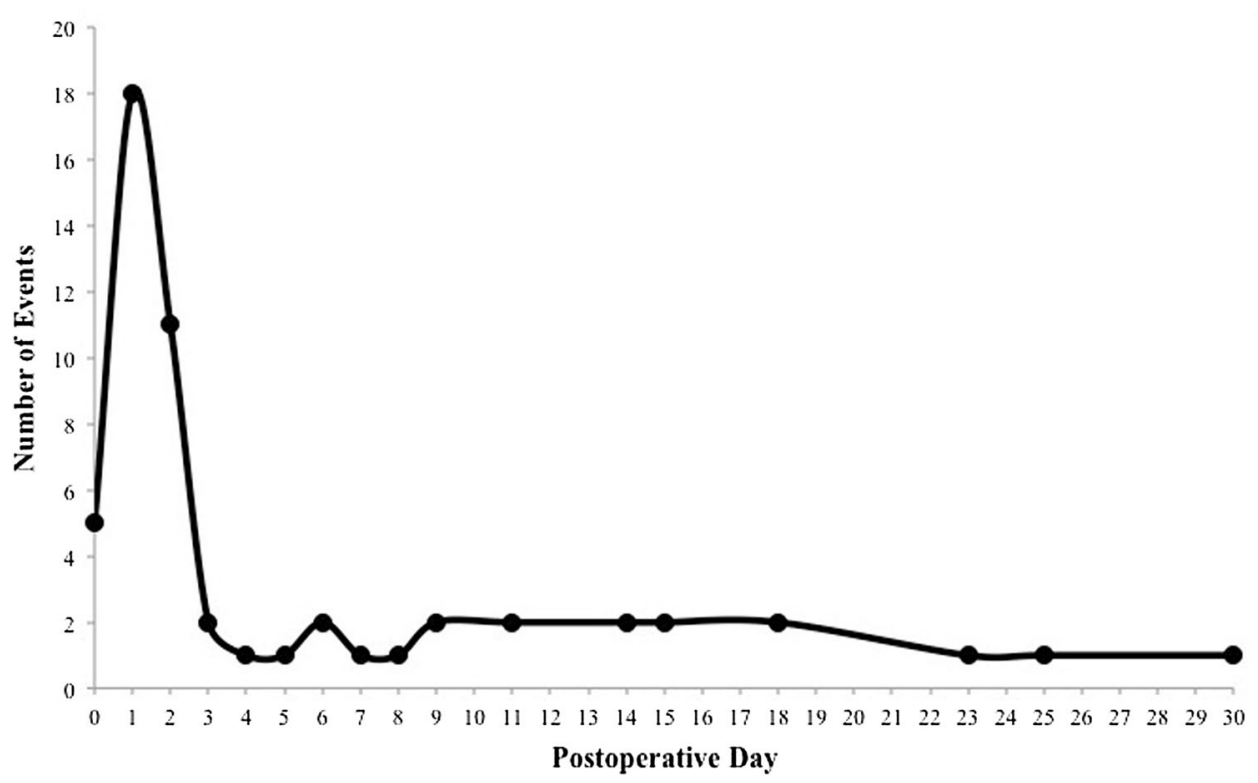

Fig. 3 Distribution of timing of cerebrovascular accidents is shown.

\section{Results}

Fifty-five of 42,150 patients $(0.13 \%)$ experienced a CVA within 30 days of the procedure, which is comparable to proportions of patients experiencing CVA after general surgery procedures. The proportion of patients with a 30 day CVA was $0.08 \%$ for TKA, $0.15 \%$ for THA, $0.00 \%$ for single-level anterior cervical discectomy and fusion, $0.38 \%$ for multilevel anterior cervical discectomies and fusions, $0.20 \%$ for single-level posterior or posterolateral lumbar fusion, $0.70 \%$ for multilevel posterior or posterolateral lumbar fusions, and $0.22 \%$ for total shoulder arthroplasty (Fig. 2). CVA occurred a median of 2 days (range, 1-30 days) after the index procedure, with the majority of events occurring on postoperative Day 1 (Fig. 3). A total of 15 events $(27 \%)$ occurred after hospital discharge and four patients $(7 \%)$ who had a CVA died during the 30-day surveillance period.

After controlling for potentially confounding variables, specific patient and procedural characteristics were shown to be independent risk factors for 30-day CVA after elective orthopaedic surgery. These variables included age of 75 years or older (odds ratio [OR], 2.50; 95\% CI, 1.44 4.35; $\mathrm{p}=0.001)$, insulin-dependent diabetes mellitus (OR, 3.08; CI, 1.47-6.45; $\mathrm{p}=0.003)$, hypertension (OR, 2.71; CI, 1.19-6.13; p = 0.017), history of transient ischemic attack (OR, 2.83; CI, 1.24-6.45; p = 0.013), dyspnea (OR, 2.51; CI, 1.30-4.86; $\mathrm{p}=0.006)$, chronic obstructive 
Table 2. Multivariate analysis of risk factors for CVA

\begin{tabular}{|c|c|c|c|}
\hline Preoperative or operative variable & Odds ratio & $95 \%$ confidence interval & $\mathrm{p}$ Value \\
\hline Male sex & 1.26 & $0.73-2.18$ & 0.402 \\
\hline Age $\geq 75$ years & 2.50 & $1.44-4.35$ & $0.001 *$ \\
\hline Insulin-dependent diabetes mellitus & 3.08 & $1.47-6.45$ & $0.003^{*}$ \\
\hline Hypertension & 2.71 & $1.19-6.13$ & $0.017 *$ \\
\hline History of myocardial infarction or percutaneous coronary intervention & 1.67 & $0.81-3.42$ & 0.164 \\
\hline History of transient ischemic attack & 2.83 & $1.24-6.45$ & $0.013^{*}$ \\
\hline Dyspnea & 2.51 & $1.30-4.86$ & $0.006^{*}$ \\
\hline Chronic obstructive pulmonary disease & 2.33 & $1.06-5.13$ & $0.036^{*}$ \\
\hline General anesthesia & 1.57 & $0.81-3.05$ & 0.181 \\
\hline Operative time $\geq 3$ hours & 3.25 & $1.60-6.60$ & $0.001 *$ \\
\hline TKA & 0.61 & $0.33-1.12$ & 0.108 \\
\hline Multilevel anterior cervical discectomy and fusion & 2.66 & $0.62-11.48$ & 0.190 \\
\hline Multilevel posterior or posterolateral lumbar fusion & 1.84 & $0.69-4.94$ & 0.224 \\
\hline
\end{tabular}

* Statistical significance $(\mathrm{p} \leq 0.05) ; \mathrm{CVA}=$ cerebrovascular accident.

pulmonary disease (OR, 2.33; CI, 1.06-5.13; p $=0.036$ ), and operative time of 180 minutes or more (OR, 3.25; CI $1.60-6.60 ; p=0.001$ ) (Table 2). The c-statistic was calculated to be 0.879 , showing good model predictability.

\section{Discussion}

Stroke is one of the most dreaded complications after surgery, and to provide adequate preventive and therapeutic measures, it is essential that surgeons ascertain which patients are at high risk for these adverse events. Postoperative stroke rates have varied depending on research methodology and surgical population and have remained stable despite surgical advances, potentially reflecting an aging population with increasing concomitant comorbidities [30, 37]. Unfortunately, relatively few orthopaedic studies have examined perioperative cerebrovascular events [11, 22, 24, 29, 32]. We therefore sought to assess the rates and predictors of CVA after common elective inpatient orthopaedic procedures to provide physicians a more accurate glimpse of this potential morbidity. Recognition of the incidence, risks, and timing of CVA after surgery is crucial for informed consent, patient preoperative counseling, treatment decisions, and potential prophylaxis in the critical postoperative period for patients at high-risk.

When evaluating our results, the limitations must be kept in mind, most of which are intrinsic constraints of the ACS NSQIP ${ }^{\circledR}$ database. First, our data assess only 30-day complications, and although the majority of CVAs in patients having noncardiac surgery occur in this interval, some CVAs undoubtedly occur later, therefore it is likely that CVA rates are somewhat higher than those we report [19]. Additionally, the ACS NSQIP ${ }^{\circledR}$ database does not differentiate between ischemic and hemorrhagic stroke, and although studies [6, 23, 34] have shown that the majority of perioperative strokes is ischemic, we are unable to comment on the specific proportions in our study. Moreover, although the ACS NSQIP ${ }^{\mathbb{R}}$ database contains a comprehensive list of preoperative and operative variables, certain predictors of CVA (such as atrial fibrillation and carotid stenosis) are not included, which may be potential confounders in our results [9, 12]. Additionally, although our study captures a large national sample size, the ACS NSQIP ${ }^{\circledR}$ database does not contain information regarding institution type (community versus academic), surgical volume, institution-specific postoperative protocols, surgeon experience, geographic location, use of chemical thromboprophylaxis, prevention of perioperative bleeding using chemoprophylaxis (such as tranexamic acid), and type of fixation in TKA and in THA (cemented versus uncemented), all of which may play a role in CVA rates. Finally, the treatment for CVA (tissue plasminogen activator versus other pharmacologic treatment) was not recorded in the ACS NSQIP ${ }^{\mathbb{R}}$ database.

Our results show that of patients undergoing elective orthopaedic surgery, $0.08 \%$ to $0.70 \%$ of them experience a 30-day CVA, depending on the procedure. Similar proportions were seen in previous reports of CVA in joint arthroplasty but our findings show a higher percentage than in reports of CVA after posterior lumbar arthrodesis [2224]. A potential explanation for this discrepancy may be the differences in the source of data between the studies, as the National (Nationwide) Inpatient Sample (NIS) captures only predischarge events unlike the ACS NSQIP ${ }^{\circledR}$, 
therefore leading to lower proportions of postoperative CVA $(0.15 \%)$ [5]. In addition, our study expands on previously known literature owing to a larger, national cohort of patients. The majority (62\%) of postoperative strokes occurred within 2 days after surgery with a peak incidence on postoperative Day 1, but more than $1 / 4$ of these adverse events appear after hospital discharge. Mortazavi et al. [29] reported that patients experienced a postoperative CVA primarily on postoperative Day 1, with 25 of 36 patients (69\%) experiencing a CVA within the first 2 days after TKA or THA. Our study expands on their data through a larger number of patients, and with the inclusion of nonarthroplasty cases which follow a similar temporal pattern. This information regarding timing of CVAs is important for postoperative in-house monitoring of high-risk patients and appropriate followup timing succeeding hospital discharge.

Although our study identified several important patientand procedure-related risk factors for postoperative CVA that previously have been associated with CVA in orthopaedic surgery, others such as insulin-dependent diabetes mellitus, hypertension, chronic obstructive pulmonary disease, and long operative times were not formerly identified. Similar to the results in our study, a previous report in the orthopaedic literature identified increased age as a risk factor for CVA [24]. A higher comorbidity burden appears with advanced age, and rates of perioperative CVA are significantly increased in the elderly [2, 20]. Diabetes, hypertension, chronic obstructive pulmonary disease, and increased operative time, however, were reported not to be independently associated with CVA after elective orthopaedic surgery [24, 29]. However, this may be attributable to insulin-dependent diabetes mellitus not being separated from noninsulin-dependent diabetes mellitus, there were smaller patient cohorts, and/or the exclusion of postdischarge CVAs with the NIS, which may have contributed to these discrepancies. Insulin-dependent diabetes mellitus has been linked to advanced atherosclerosis and ischemic stroke, whereas uncontrolled hypertension is associated with ischemic and hemorrhagic CVA in the general population [13, 35]. Moreover, chronic obstructive pulmonary disease recently was shown to be associated with carotid artery wall thickening, placing patients at greater danger for ischemic events [21]. Furthermore, advanced operative time has been linked to numerous postoperative adverse events after orthopaedic surgery, potentially owing to the effect of anesthesia time or to a more complicated procedure $[3,36]$. An important difference in the results of our study with those of Mortazavi et al. [29] is that general anesthesia was not independently associated with CVA. Once again, this may have stemmed from differences in patient characteristics between the two studies and the larger number of patients in our study, along with different preoperative variable inclusions. Although our results show that a history of transient ischemic attack is a predictor of CVA, paradoxically, history of CVA was not independently associated with 30-day CVA rates [10]. An explanation for this incongruity may be that patients with previous CVA may have been receiving anticoagulants before surgery thereby preventing perioperative strokes, whereas patients with only a history of transient ischemic attack may not have had this previous prophylaxis. Additionally, previous CVA may have been embolic-for example, from mural thrombi in patients with a history of atrial fibrillation or patent foramen ovale - which may have been controlled and treated before surgery. On the basis of these findings, we recommend that patients older than 75 years, those who have undergone a procedure longer than 3 hours, or with insulin-dependent diabetes mellitus, hypertension, history of transient ischemic attack, dyspnea, or chronic obstructive pulmonary disease should be managed and followed more stringently in the immediate postoperative period after orthopaedic surgery by those involved their postoperative care. These patients may be targets for preoperative pharmacologic prophylaxis in the future $[7,25]$.

We present an analysis of 30-day CVAs after elective orthopaedic surgery in a large, national sample. Orthopaedic surgeons should be aware that the majority of postoperative CVAs occur by postoperative Day 2 , and patients at high risk should be monitored more closely during this time. Although many associated patient comorbidities are not modifiable, physicians should be aware of these patients for preoperative counseling and risk stratification, while limiting operative time to reduce the risk of perioperative CVAs. Future studies should examine the association of other patient comorbidities such as noncoronary heart disease and atrial fibrillation on CVA in the orthopaedic population for more definitive recommendations.

\section{References}

1. American College of Surgeons National Surgical Quality Improvement Program $^{\circledR}$ (ACS NSQIP ${ }^{\mathbb{R}}$ ). Available at: https:// www.facs.org/quality-programs/acs-nsqip. Accessed April 28, 2015.

2. Bateman BT, Schumacher HC, Wang S, Shaefi S, Berman MF. Perioperative acute ischemic stroke in noncardiac and nonvascular surgery: incidence, risk factors, and outcomes. Anesthesiology. 2009;110:231-238.

3. Belmont PJ Jr, Goodman GP, Waterman BR, Bader JO, Schoenfeld AJ. Thirty-day postoperative complications and mortality following total knee arthroplasty: incidence and risk factors among a national sample of 15,321 patients. J Bone Joint Surg Am. 2014;96:20-26. 
4. Birkmeyer JD, Shahian DM, Dimick JB, Finlayson SR, Flum DR, Ko CY, Hall BL. Blueprint for a new American College of Surgeons: National Surgical Quality Improvement Program. J Am Coll Surg. 2008;207:777-782.

5. Bohl DD, Basques BA, Golinvaux NS, Baumgaertner MR, Grauer JN. Nationwide Inpatient Sample and National Surgical Quality Improvement Program give different results in hip fracture studies. Clin Orthop Relat Res. 2014;472:1672-1680.

6. Brooker RF, Brown WR, Moody DM, Hammon JW Jr, Reboussin DM, Deal DD, Ghazi-Birry HS, Stump DA. Cardiotomy suction: a major source of brain lipid emboli during cardiopulmonary bypass. Ann Thorac Surg. 1998;65:1651-1655.

7. Brooks DC, Schindler JL. Perioperative stroke: risk assessment, prevention and treatment. Curr Treat Options Cardiovasc Med. 2014;16:282.

8. Bucerius J, Gummert JF, Borger MA, Walther T, Doll N, Onnasch JF, Metz S, Falk V, Mohr FW. Stroke after cardiac surgery: a risk factor analysis of 16,184 consecutive adult patients. Ann Thorac Surg. 2003;75:472-478.

9. Davis SM, Donnan GA. Carotid-artery stenting in stroke prevention. N Engl J Med. 2010;363:80-82.

10. Dutta D, Bowen E, Foy C. Four year follow up of transient ischemic attacks, strokes, and mimics: a retrospective transient ischemic attack clinic cohort study. Stroke. 2015;46:1227-1232.

11. Friedman DJ, Parnes NZ, Zimmer Z, Higgins LD, Warner JJ. Prevalence of cerebrovascular events during shoulder surgery and association with patient position. Orthopedics. 2009;32:pii: orthosupersite.com/view.asp?rID=38058.

12. Giardina EG. Atrial fibrillation and stroke: elucidating a newly discovered risk factor. Am J Cardiol. 1997;80:11D-18D; discussion 35D-39D.

13. Gregg EW, Li Y, Wang J, Burrows NR, Ali MK, Rolka D, Williams DE, Geiss L. Changes in diabetes-related complications in the United States, 1990-2010. N Engl J Med. 2014;370:15141523.

14. Gutierrez IZ, Barone DL, Makula PA, Currier C. The risk of perioperative stroke in patients with asymptomatic carotid bruits undergoing peripheral vascular surgery. Am Surg. 1987;53:487489.

15. Helwani MA, Avidan MS, Ben Abdallah A, Kaiser DJ, Clohisy JC, Hall BL, Kaiser HA. Effects of regional versus general anesthesia on outcomes after total hip arthroplasty: a retrospective propensity-matched cohort study. J Bone Joint Surg Am. 2015;97:186-193.

16. Kam PC, Calcroft RM. Peri-operative stroke in general surgical patients. Anaesthesia. 1997;52:879-883.

17. Kester BS, Merkow RP, Ju MH, Peabody TD, Bentrem DJ, Ko $\mathrm{CY}$, Bilimoria KY. Effect of post-discharge venous thromboembolism on hospital quality comparisons following hip and knee arthroplasty. J Bone Joint Surg Am. 2014;96:1476-1484.

18. Khuri SF, Henderson WG, Daley J, Jonasson O, Jones RS, Campbell DA Jr, Fink AS, Mentzer RM Jr, Neumayer L, Hammermeister K, Mosca C, Healey N; Principal Investigators of the Patient Safety in Surgery Study. Successful implementation of the Department of Veterans Affairs' National Surgical Quality Improvement Program in the private sector: the Patient Safety in Surgery study. Ann Surg. 2008;248:329-336.

19. Kikura M, Bateman BT, Tanaka KA. Perioperative ischemic stroke in non-cardiovascular surgery patients. J Anesth. 2010;24: 733-738.

20. Kikura M, Oikawa F, Yamamoto K, Iwamoto T, Tanaka KA, Sato S, Landesberg G. Myocardial infarction and cerebrovascular accident following non-cardiac surgery: differences in postoperative temporal distribution and risk factors. J Thromb Haemost. 2008;6:742-748.
21. Lahousse L, van den Bouwhuijsen QJ, Loth DW, Joos GF, Hofman A, Witteman JC, van der Lugt A, Brusselle GG, Stricker $\mathrm{BH}$. Chronic obstructive pulmonary disease and lipid core carotid artery plaques in the elderly: the Rotterdam Study. Am J Respir Crit Care Med. 2013;187:58-64.

22. Lalmohamed A, Vestergaard P, Cooper C, de Boer A, Leufkens HG, van Staa TP, de Vries F. Timing of stroke in patients undergoing total hip replacement and matched controls: a nationwide cohort study. Stroke. 2012;43:3225-3229.

23. Limburg M, Wijdicks EF, Li H. Ischemic stroke after surgical procedures: clinical features, neuroimaging, and risk factors. Neurology. 1998;50:895-901.

24. Marquez-Lara A, Nandyala SV, Fineberg SJ, Singh K. Cerebral vascular accidents after lumbar spine fusion. Spine (Phila $\mathrm{Pa}$ 1976). 2014;39:673-677.

25. Mashour GA, Moore LE, Lele AV, Robicsek SA, Gelb AW. Perioperative care of patients at high risk for stroke during or after non-cardiac, non-neurologic surgery: consensus statement from the Society for Neuroscience in Anesthesiology and Critical Care*. J Neurosurg Anesthesiol. 2014;26:273-285.

26. McKhann GM, Grega MA, Borowicz LM Jr, Baumgartner WA, Selnes OA. Stroke and encephalopathy after cardiac surgery: an update. Stroke. 2006;37:562-571.

27. Merkow RP, Bilimoria KY, Hall BL. Interpretation of the Cstatistic in the context of ACS-NSQIP models. Ann Surgical Oncol. 2011;18(suppl 3):S295; author reply S296.

28. Minhas SV, Ho BS, Switaj PJ, Ochenjele G, Kadakia AR. A comparison of 30-day complications following plate fixation versus intramedullary nailing of closed extra-articular tibia fractures. Injury. 2015;46:734-739.

29. Mortazavi SM, Kakli H, Bican O, Moussouttas M, Parvizi J, Rothman RH. Perioperative stroke after total joint arthroplasty: prevalence, predictors, and outcome. J Bone Joint Surg Am. 2010;92:2095-2101.

30. Mozaffarian D, Benjamin EJ, Go AS, Arnett DK, Blaha MJ, Cushman M, de Ferranti S, Despres JP, Fullerton HJ, Howard VJ, Huffman MD, Judd SE, Kissela BM, Lackland DT, Lichtman JH, Lisabeth LD, Liu S, Mackey RH, Matchar DB, McGuire DK, Mohler ER 3rd, Moy CS, Muntner P, Mussolino ME, Nasir K, Neumar RW, Nichol G, Palaniappan L, Pandey DK, Reeves MJ, Rodriguez CJ, Sorlie PD, Stein J, Towfighi A, Turan TN, Virani SS, Willey JZ, Woo D, Yeh RW, Turner MB; American Heart Association Statistics Committee and Stroke Statistics Subcommittee. Heart disease and stroke statistics-2015 update: a report from the American Heart Association. Circulation. 2015;131: e29-322.

31. Murray CJ, Lopez AD. Alternative projections of mortality and disability by cause 1990-2020: Global Burden of Disease Study. Lancet. 1997;349:1498-1504.

32. Pedersen AB, Mehnert F, Sorensen HT, Emmeluth C, Overgaard $\mathrm{S}$, Johnsen SP. The risk of venous thromboembolism, myocardial infarction, stroke, major bleeding and death in patients undergoing total hip and knee replacement: a 15-year retrospective cohort study of routine clinical practice. Bone Joint J. 2014;96:479-485.

33. Peduzzi P, Concato J, Kemper E, Holford TR, Feinstein AR. A simulation study of the number of events per variable in logistic regression analysis. J Clin Epidemiol. 1996;49:1373-1379.

34. Restrepo L, Wityk RJ, Grega MA, Borowicz L Jr, Barker PB, Jacobs MA, Beauchamp NJ, Hillis AE, McKhann GM. Diffusionand perfusion-weighted magnetic resonance imaging of the brain before and after coronary artery bypass grafting surgery. Stroke. 2002;33:2909-2915.

35. Sacco RL, Benjamin EJ, Broderick JP, Dyken M, Easton JD, Feinberg WM, Goldstein LB, Gorelick PB, Howard G, Kittner SJ, 
Manolio TA, Whisnant JP, Wolf PA. American Heart Association Prevention Conference. IV. Prevention and rehabilitation of stroke: risk factors. Stroke. 1997;28:1507-1517.

36. Schoenfeld AJ, Ochoa LM, Bader JO, Belmont PJ Jr. Risk factors for immediate postoperative complications and mortality following spine surgery: a study of 3475 patients from the National
Surgical Quality Improvement Program. J Bone Joint Surg Am. 2011;93:1577-1582.

37. Selim M. Perioperative stroke. N Engl J Med. 2007;356:706-713.

38. Wong GY, Warner DO, Schroeder DR, Offord KP, Warner MA, Maxson PM, Whisnant JP. Risk of surgery and anesthesia for ischemic stroke. Anesthesiology. 2000;92:425-432. 